\title{
Introduction: \\ In the Shadow of Mainland China: Changing Ethnic Chinese Business Practices in Southeast Asia
}

\author{
Michael Jacobsen and Ng Beoy Kui (Guest Editors)
}

It has been argued that one of the main reasons behind Mainland China's post 1978 rise to its current status as a global economic superpower has been particularly the economic success of Southeast Asian Chinese entrepreneurs, who sent huge amounts of foreign direct investments (FDI) to China in order to develop, and thus tap into, this emerging market. The success of these entrepreneurs has generally been attributed to some shared cultural characteristics with Mainland Chinese entrepreneurs. This was particularly based on Confucian values that govern an array of economic practices such as guanxi (dyadic (business) relations), xinyong (trust) and the importance of family relations, all economic practices which had their origin in China itself. Due to the perceived cultural affinity between Chinese entrepreneurs from Mainland China and Southeast Asia, it was imagined that this would facilitate investment opportunities between the two groups of Chinese entrepreneurs. According to such a culturalist perspective, there was thus a perfect match between an opening Mainland China, with its low labour costs and huge domestic market, and ethnic Chinese investors living outside Mainland China, who were eager to invest in this promising market, so benefiting the overall relationship between China and the Southeast Asian countries, where the bulk of ethnic Chinese resided. ${ }^{1}$

$\mathrm{Ng}$ Beoy Kui, in the first article of this special issue, deals with this match between China and the Southeast Asian economies. He examines the economic impact of China on the Southeast Asian countries, mainly in terms of trade and investment. He raises the question of whether the rise of China poses a threat to Southeast Asia as a region with regard to international trade, or whether both parties can collaborate based on their common interests in promoting economic growth. $\mathrm{Ng}$ Beoy Kui goes on to question whether the concentration of FDI in China implies a diversion of FDI away from Southeast Asia. Does the FDI in China and Southeast Asian region support each party in the international division 
of labour? He argues that the increasing role of China as an international trader and global investor provides a golden opportunity for Southeast Asian countries to integrate their ethnic Chinese economy. The huge domestic Chinese market provides vast opportunities for investment, the entrance to which is facilitated through perceived notions of a common mode of doing businesses in the region. $\mathrm{Ng}$ Beoy Kui concludes that the rise of China benefits the Southeast Asian economies particularly in terms of China's role in the Asian production networks, destination for investment, its outward investment and, more importantly, its huge and growing domestic market. According to the author, this turns China into yet another driver for economic growth in Asia.

However, the rise of China as mainly a manufacturing powerhouse also poses a threat to the Southeast Asian economies. Taking a point of departure in the fluid political and economic landscape of East and Southeast Asia, the contribution by Michael Jacobsen focuses on ethnic Chinese SME entrepreneurs in Southeast Asia, especially in Indonesia and Malaysia. He argues that they are gradually becoming a kind of hostage in the discussion of whether a rising Mainland Chinese economy is a benevolent or predatory force in the Asian region. Contrary to the coherent nature otherwise ascribed to this particular ethnic group, Michael Jacobsen argues that, in fact, it is divided into many different factions. This differentiation of the ethnic Chinese community particularly in Southeast Asia, it is argued, is a reflection of multi-dimensional impacts from colonialism and different contemporary social and political developments within the individual Southeast Asian country in which the ethnic Chinese live. This increasing societal complexity makes the ethnic Chinese entrepreneurs vulnerable in the wake of a rising Mainland Chinese economy. The latter can impact either positively or negatively on the various Southeast Asian economies, thus indirectly influencing the processes of societal embedding of their respective ethnic Chinese minorities. As a consequence, the otherwise attractive Chinese market has both positive and negative connotations.

Going beyond the impact of culture on Southeast Asian Chinese business practices, and taking a rapidly changing business environment into account, the contribution by Menkhoff et al examines the organisational change management behaviour of the owner-managers of small and medium-sized enterprises in Singapore. The analysis of survey data aims at ascertaining whether there are any differences between Chinese and English educated (Chinese) small businessmen in terms of Change Management, a dichotomy that is of great historical and politico-cultural 
significance in Singapore. The survey data collected by the authors show that there are indeed differences between the subgroups (e.g. with regard to the initiation of a more participatory people management style). However, these variations turned out to be far less pronounced than expected. Access to information and actionable managerial knowledge appears to be a key antecedent of the various Change Management approaches used by both groups. Chinese educated businessmen in particular seem to be somewhat disadvantaged in this respect, as the modern Change Management literature is still largely published in English.

The article by Ramin and Ziemnowicz takes us to a more general level in the discussion of entrepreneurial activities, although the discussion stills relates specifically to Singapore. According to them, there are more general ramifications in this connection for the Southeast Asian business community that has to be taken into account. Creativity and risk-taking, widely accepted prerequisites for successful entrepreneurial behaviour, were, according to Ramin and Ziemnowicz, absent for a long time from the Singaporean community, accustomed as it was to well paid and readily available jobs in the public sector. Promoting entrepreneurial activities thus became a priority of the Singapore government in the last decade as a result of the economic slowdown in the late 1990s. Using this environment for measuring entrepreneurship in Singapore, Ramin and Ziemnowicz then analysed the entrepreneurial characteristics of Singapore's multi-racial and multi-cultural society in search of differences in the propensity to engage in entrepreneurship based on factors such as race, gender, and culture. Their main finding is that the economic policies of the Singapore government have been hugely successful in increasing growth and affluence. These achievements may, according to Ramin and Ziemnowicz, have led Singaporeans, especially the younger generation, to be complacent, heightening their reluctance to leave their comfort zone. This has resulted in their inability to realize the need for diligence and determination. In addition, while the abundance of employment opportunities provides a safety net for the working adults, in actual fact it may have reduced their level of determination, as they lack motivation and perhaps the ability to face the obstacles that are an inherent aspect of innovative entrepreneurial endeavours.

As mentioned previously, Southeast Asian Chinese businesses can be characterised as possessing some unique cultural attributes. Fock Siew Tong et al argue in their contribution, that being embedded in culturally specific institutional environments might hold back the growth of these Chinese businesses, thus leading them to take on limited or altruistic 
economic roles in their respective Southeast Asian home countries. Familism, particularism, nepotism and the lack of state support, it is argued, stand in the way of developing large, successful and enduring firms, problems that are further aggravated by inter-generational transitions that frequently lead to their demise. Sounding a more optimistic note, the authors argue that such fatalistic prognoses are misplaced. They introduce some case studies of successful Chinese family businesses in Singapore to demonstrate how business leaders, as agents, can incorporate, defy, or recombine elements from the socio-cultural environment in ways that enable continuity and growth. Furthermore, Fock Siew Tong et al highlight the important role of a proactive state in promoting a specific Chinese mode of doing business based on notions of so-called Confucian capitalism, which despite its culturalist image, is based on pragmatic capitalist practices.

As can be seen, all five articles in this special issue of Copenhagen Journal of Asian Studies point to the fact that being an entrepreneur of Chinese descent in Southeast Asia does not imply that culture plays an omnipotent and determining role when engaging in business as otherwise generally presumed. On the contrary, due to statist interventions combined with complex inter-ethnic relations and increasing entrenchment of global capitalism, current Southeast Asian Chinese business practices do not correspond to the stereotypical notion of Chinese capitalism based on Confucian values or any other specific Chinese modes of doing business. Rather, they have to respond to ever changing political and economic conditions in order to adapt to local environmental imperatives. By not doing so, they run the risk of not only experiencing worsening inter-ethnic relations with the dominant 'other', but also potentially loosing out in the economic sphere, be it domestically or internationally, as cultural mores do not relate well to global market mechanisms. In such a complex context, the Mainland Chinese market is not only conceived of as a golden opportunity for doing business, but also as a potential problematic factor that has to be taken into account when doing business in a Southeast Asian context.

Michael Jacobsen is Associate Professor at Asia Research Centre, Copenhagen Business School, and $\mathrm{Ng}$ Beoy Kui is Associate Professor at School of Humanities and Social Science, Nanyang Technological University, Singapore.

\section{Notes}

1 For a critique of the culturalist approach to ethnic Chinese entrepreneurship, see Michael Jacobsen this volume. 